\title{
Three cases of the maxillary artery in an abnormal course - penetrating the mandibular nerve-
}

\author{
Akimichi Takemura, Fumihiko Suwa, Jun Nakajima, \\ Takuzo Otsuka and Seiichi Saitoh \\ Department of Anatomy (Director: Prof. Yoshikuni Ohta), Osaka Dental University, \\ 1-47 Kyobashi, Higashi-ku, Osaka 540, Japan
}

[Accepted for publication: October 13, 1983]

Key words: abnormalities / maxillary artery / mandibular nerve / pterygoid muscles

\section{Findings}

Three variational cases, in which the maxillary artery passed medial to the lateral pterygoid muscle and penetrated the mandibular nerve, were found in cadavers for dissection use by students. This artery in one case had penetrated between the inferior alveolar and lingual nerves, and in the other two cases had penetrated the inferior alveolar nerve itself. These three cases belong to type $\mathrm{D}$ in the classification of locational relations between the maxillary artery, the mandibular nerve and the lateral pterygoid muscle by Fujita $(1932)^{1)}$. Additionally, variations in the arising order of branches of the maxillary artery were found to some extent in the three cases.

Case 1. (right side, Figs. 1a, 1b) :

The maxillary artery, separated from the superficial temporal artery posteroinferior to the mandibular cervix, gave rise to a common trunk between the deep auricular, the anterior tympanic and a common trunk between the inferior alveolar, the posterior deep temporal and the masseteric arteries from its lateral wall anteroinferolaterally. The parent artery was bent anteromedially and passed medial to the inferior head of the lateral pterygoid muscle, while the latter trunk ran anterosuperiorly lateral to this muscle as the maxillary artery does in usual cases, and terminated in the deep temporal and the masseteric after giving off the inferior alveolar artery and the lingual branch. Medial to the lateral pterygoid, the maxillary artery gave rise to the middle meningeal from the medial wall superomedially and fine pterygoid branches, and passed forward into the pterygopalatine fossa, giving off the buccal artery anteroinferolaterally, after passing between the inferior alveolar and the lingual nerves.

Case 2. (left side, Figs. 2a, 2b) :

The maxillary artery gave rise to a common trunk between the deep auricular and the anterior tympanic, and a common trunk between the inferior alveolar, the posterior deep temporal and the masseteric, then the middle meningeal medial to the lateral pterygoid muscle superomedially and the lingual branch anteroinferiorly at the same level. Immediately after these branchings the artery penetrated the inferior alveolar nerve. By this penetration, this nerve was divided into one considerably thin nerve bundle in the lateral side of this artery and the other thick bundle on the medial side. The buccal artery, diverged from the maxillary in a position where the same named nerve passed lateral to this artery.

Case 3. (right side, Fig. 3) :

The maxillary artery gave rise to two such common trunks as observed in case 2 . The lingual branch arose from the inferior alveolar. This artery passed between the inferior alveolar nerve and the communicating branch between it and the lingual nerve, after sending off the middle meningeal. The 

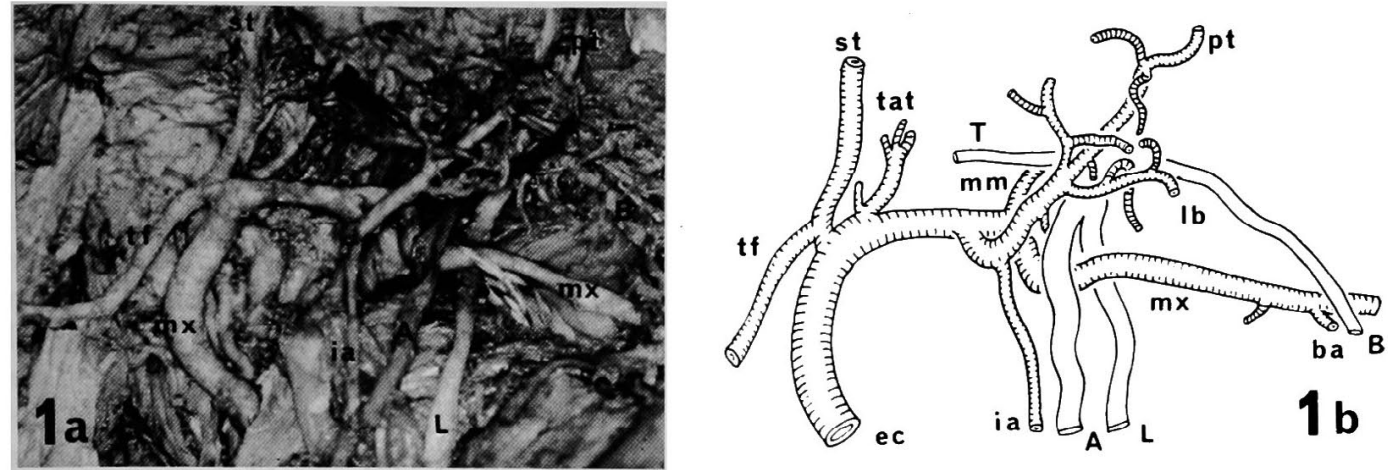

Figs. 1a, 1b. Case 1. Lateral view of the right side.
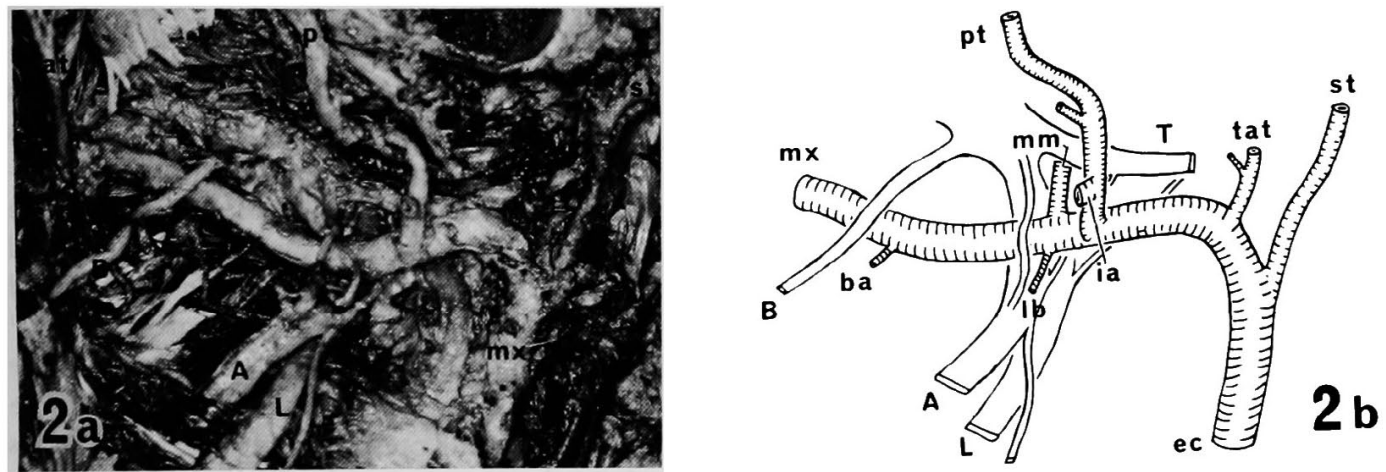

Figs. 2a, 2b. Case 2. Lateral view of the left side.

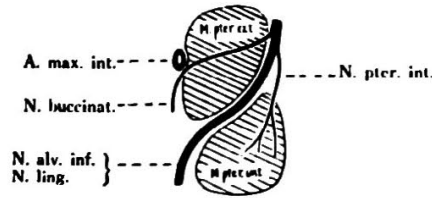

Typus $\mathbf{A}$.

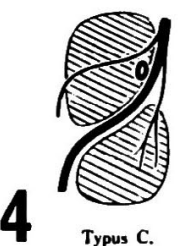

Fig. 4 Fujita's (1932)" classification of the locational relations between the maxillary artery, the mandibular nerve and the lateral pterygoid muscle.

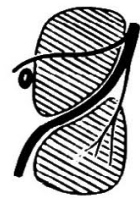

Typus B.

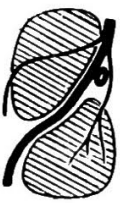

Typus E.

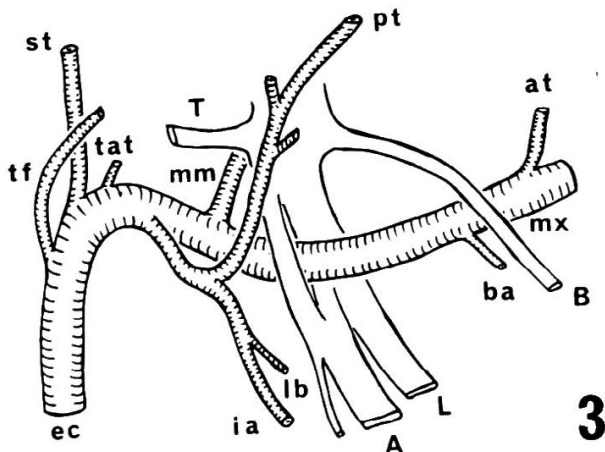

Fig. 3 Case 3. Schema. Lateral view of the right side.

\section{Abbreviations}

at: Anterior deep temporal artery, ba: Buccal artery, ec: External carotid artery, ia: Inferior alveolar artery, lb: Lingual branch, $\mathrm{mm}$ : Middle meningeal artery, $\mathrm{mx}$ : Maxillary artery, pt: Postericr deep temporal artery, st: Superficial temporal artery, tat: A common trunk between the deep auricular and the anterior tympanic arteries, tf: Transverse facial artery, A: Inferior alveolar nerve, B: Buccal nerve, L: Lingual nerve, T: Auriculotemporal nerve 
buccal artery and nerve were similar to those in case 1. Additionally, the transverse facial artery arose directly from the external carotid, proximal to the bifurcation into the superficial temporal and the maxillary arteries.

\section{Discussion}

The course of the maxillary artery usually is located lateral to the lateral pterygoid muscle in Japanese, but medial to it in about a half percent of European. This difference was first pointed out by Adachi $(1928)^{2}$, and was followed by Fujita (1932) ${ }^{11}$, Takarada $(1958)^{3)}$, Ikakura $(1961)^{4)}$. Fujita ${ }^{1)}$ took notice of the locational relations between the maxillary artery and the lateral pterygoid muscle, including the mandibular nerve. $\mathrm{He}$ thus classified the relations between three subjects into five types A-E (Fig. 4). Takarada ${ }^{3)}$ and Ikakura ${ }^{4}$ attempted to use his classification in their reported cases. As pointed out by Adachi ${ }^{2}$, it is rare for the maxillary artery to pass medial to the lateral pterygoid and the mandibular nerve (type E), and penetrate this nerve (type D), as shown in Table 1.

Table 1 Frequency ratio in cases in which the maxillary artery passes medial to the mandibular nerve (type E), and penetrates it (type D) in Japanese

\begin{tabular}{lccc}
\hline & Type D & Type E & Total \\
\hline Adachi $^{2)}$ & $1(0.3 \%)$ & $1(0.3 \%)$ & 331 \\
Fujita $^{1)}$ & $2(1.7 \%)$ & $2(1.7 \%)$ & 119 \\
Takarada $^{3)}$ & $1(0.8 \%)$ & $3(2.5 \%)$ & 120 \\
Ikakura $^{4)}$ & $1(0.6 \%)$ & $3(1.9 \%)$ & 160 \\
\hline
\end{tabular}

In comparative angiology, Tandler $(1899)^{5)}$ investigated the locational relation between the maxillary artery and the mandibular nerve in many mammals. Also, results obtained from comparative angiological studies in the department of the present authors are similar to Tandler's findings: for example, this artery passes medial to the mandibular nerve in the dog, cat, rabbit; lateral to it in the crab-eating monkey. After all, the locational relations between them can probably be determined by species.

As regards the relation between the maxillary artery and the mandibular nerve, Padget $(1948)^{6)}$ stated that anastomosis between the external carotid and the stapedial artery in the early stage (20-24 mm length) of the human embryo formed a loop on both the medial and lateral sides of this nerve, and later, the lateral crus of the loop developed into the maxillary after the disappearance of the medial crus. Accordingly, the similarity between monkey and man seems to occur during the developmental process. On the contrary, disappearance of the lateral crus of the loop may occur, and the medial crus may develop into the maxillary artery passing medial to the mandibular nerve in the dog and rabbit. However, Tandler ${ }^{5)}$ and Padget $^{6)}$ did not dwell on the locational relations mentioned above. Kimura (1982) ${ }^{\text {?) }}$ described that the maxillary artery of the rabbit passed medial to the mandibular nerve and the lateral pterygoid muscle in 160 sides of 80 heads observed. This feature corresponds to type E by Fujita ${ }^{1)}$ in man. Suwa $(1981)^{8)}$ stated that this artery of the crab-eating monkey passed lateral to this nerve and muscle in 39 sides of 20 heads observed. This feature corresponds to type $A$ and $B$ in man. In these species, the course of the maxillary artery was not variable but constant against the location of these elements. On the contrary, the maxillary artery of the cat, as stated by Takemura (1982) ${ }^{9)}$ in his work which investigated the rete mirabile of this artery, passed medial to the mandibular nerve and the lateral pterygoid muscle in 88 of 90 examples observed $(97.8 \%)$ (type $\mathrm{E}$ in man) and lateral to both elements in two only $(2.2 \%)$. The frequency in the cat is quite opposite of that in man. Such variations in the course of the maxillary artery may be found in other mammals, if investigations were to be directed toward the relations between the elements mentioned above in many species.

In addition, the middle meningeal, the inferior alveolar and the posterior deep temporal usually arise from the maxillary artery 
in this order. However, when the parent artery passed medial to the lateral pterygoid muscle, the first arose distalmost to the others in the present three cases, and a common trunk was formed between the middle and the last as well. This closely resembles the ramifications (Suwa et al., 1978) ${ }^{10)}$ of the maxillary passing medial to the lateral pterygoid muscle in usual cases of the dog.

\section{References}

1) Fujita, T.: Über einem Fall von beiderseitig medial vom $\mathrm{N}$. mandibularis verlaufender $\mathrm{A}$. maxillaris interna, nebst einer Statistik der Verlaufsvariation der Arterie. J. Stomastol. Soc. Jpn. 4: 250-252, 1932. (in Japanese)

2) Adachi, B.: Das Arteriensystem der Japaner. Bd. I, Maruzen, Kyoto, 85-96, 1928.

3) Takarada, T.: Anatomical studies on the maxillary artery. J. Tokyo Dent. Coll. Soc. 58: 1-20, 1958. (in Japanese)

4) Ikakura, K.: On the origin, course and distribution of the maxillary artery in Japanese. Arch. Dept. of Anat. Tokyo Dent. Coll. (Kouku Kaibou Kenkyu) 18: 91-122, 1961. (in Japanese)

5) Tandler, J.: Zur vergleichenden Anatomie der Kopfarterien bei den Mammalia. Denkschr. Kais. Akad. Wiss. Mathematischnaturw. Klasse, Wien 67: 677-779, 1899.

6) Padget, D. H.: Development of the cranial arteries in the human embryo. Contrib. Embryol. 32: 205-262, 1948.

7) Kimura, K.: The inferior alveolar artery of the rabbit-from its origin to the mandibular foramen-. Okajimas Folia Anat. Jpn. 59: 25-44, 1982.

8) Suwa, F.: The posterior deep temporal artery of the crab-eating monkey. Okajimas Folia Anat. Jpn. 57: 347-368, 1981.

9) Takemura, A.: The rete mirabile of the maxillary artery in the cat. Okajimas Folia Anat. Jpn. 59: 103-136, 1982.

10) Suwa, F., S. Tominaga and H. Kumagai: On the posterior deep temporal artery of the dog. Okajimas Folia Anat. Jpn. 55: 255-264, 1978. 